\title{
Institute of Ethiopian Studies, Addis Ababa, Ethiopia
}

\author{
Sarah Heery ${ }^{\star}$
}

History

If you believe the media reports, Ethiopia is a depressed nation of recurring famine, drought and conflict. Although this is the daily reality for many, where $85 \%$ of people live on the land, and many survive on less than $\$ 1$ a day, Ethiopia amounts to far more than this. It is a land of unique natural beauty, a land of 13 months of sunshine. When the rest of the world adopted the Julian calendar, Ethiopia kept the Gregorian calendar with 12 months of 30 days and a 13th month of 6 days, or 7 days if it is a leap year. It is seven years behind so in 2003, it was 1996. Ethiopians work in twelve hour time cycles from sunrise to sunset. Ethiopia has its own unique writing and its own language. Amharic is the official language of Ethiopia, one of 80 indigenous languages. There are eight ethnic groups, of which the Oromo who number $54 \%$ is the largest. New year is 11 September, Christmas is 6 January.

A profoundly religious country, Judaism, Christianity and Islam have all contributed to shape Ethiopia's culture and society. A plethora of churches and monasteries, alongside religion itself, with its church music and poetry give Ethiopia its unique defining culture. Orthodox Christianity and Islam are the predominant religions, while Catholicism, Protestantism and other minority religions are also represented. The last Emperor, Haile Selassie I, was the 225th monarch in the Solominic line descended from Menelik (said to be the son of the Queen of Sheba and King Solomon). Judaism plays a key role in presentday Ethiopia combining the rituals of circumcision, fasting and Saturday's sabbath. Ethiopia still has a few of its own Falasha Jews.

Ethiopia escaped the European Scramble for Africa in the 19th century, while Eritrea, part of Ethiopia at the time, became an Italian colony. The only attempt at colonisation amounted to 5 years of Italian occupation from 19361941. The Communist government, the Dergue, overthrew Emperor Haile Selassie I and ruled from 1974-1991. While implementing much-needed social and land reforms, the Dergue did not brook any form of dissent. Rule was by fear, with assassination and execution being the norm as shocking human rights abuses were perpetrated to root out all members of the former imperial élite and opponents of the regime. In 1991 the Tigrayan-dominated government of Prime Minister Meles Zenawi took over and is still in power today. The new government's principal aims are to address food security and reform the private sector. Domestic politics has been dominated since 1998 by a border war with Eritrea. Despite a ceasefire in 2000, peace is far from established. The UN is now mediating over the demarcation of the border.

\footnotetext{
* Sarah Heery was from 1995-2003 Librarian, Christian Aid; in 2003 she was Volunteer Librarian, Institute of Ethiopian Studies; and is now a freelance Librarian/Information Consultant
} 
Ethiopian people are proud, peace-loving and resilient, armed with a spirit and endurance to face the gruelling poverty and despair of many of their lives. Today they also live under the more serious threat of the HIV/AIDS pandemic. Literacy rates are rising and a positive development is the increasing numbers of women in education. Local non-governmental organisations (NGOs) work with international agencies to improve people's lives in the areas of health, water and sanitation, education and literacy, agriculture and irrigation technologies, food security and the environment.

As the tourist industry germinates, tourists venture to northern Ethiopia to the rock-hewn churches of Tigray, the 11 th century churches in Lalibela, and the former ancient capital city of Axum, said to be the home of the Queen of Sheba. Lake Tana, the second largest lake in Africa and the source of the Blue Nile, has 30 islands which house ancient monasteries dating back to the 13 th century, some of which are closed to women, and one is reputed to preserve the oldest library in Ethiopia. There is Harar, ancient Muslim walled city to the east, while in the south, Wolaita is an area of 'green famine', where people barely have enough food to survive, but the luscious countryside belies a land of plenty. There are mountainous regions, home to the Simien fox and rare Ethiopian wolves, and the lake region in the Rift Valley.

\section{Institute of Ethiopian Studies (IES)}

Founded in 1963, by Professor Richard Pankhurst, also its first director (19631975), the Institute of Ethiopian Studies (IES) consists of an ethnological museum and library. The Institute was established to develop and promote a library and ethnological museum; to publish a fournal of Ethiopian Studies; to coordinate research and serve as a centre for Ethiopian studies in Ethiopia and internationally; and to meet the needs of the community in developing Ethiopian research and in promoting awareness and knowledge of Ethiopian culture.

The seeds of the modern IES grew back in the 1950s at a critical time in the history and development of graduate programmes in African studies in the world and also higher education in Ethiopia. It was just after the Second World War and before African studies teaching programmes were established in American or European universities. University College Addis Ababa (UCAA) was inaugurated in 1950 and its librarian wished to develop a comprehensive Ethiopica collection of works printed in Ethiopia. At the same time a collection of materials on Africa, the Horn of Africa and Ethiopia was growing as publications were widely available and inexpensive, particularly in Europe at that time.

Addis Ababa University is one of the oldest seats of learning in Africa and over the years has withstood revolutions and political upheaval. Starting as University College Addis Ababa (UCAA) in 1950, it was renamed Haile Selassie I University in 1961 and then Addis Ababa University (AAU) in 1975 after the Ethiopian revolution in 1974. Having been a subordinate section of the UCAA library, the Ethiopia collection/library was transformed into a core collection at the university and paved the way for the future IES library. The Ethiopica collection, with material on Ethiopia in foreign and Ethiopian languages, maps and microfilms, moved to its present location in the former imperial palace on the main university campus in Sidist Kilo, Addis Ababa, donated to the university by the Emperor in 1961. This all led to increased 
interest in the library, IES and the acquisition of works on Ethiopia and the Horn of Africa. To build the collection greater efforts were needed to obtain material at this time from what was becoming a rapidly-dwindling stock of Ethiopian literature in the US and Europe. In addition locally printed books needed to be acquired.

Today the Institute comprises 3 departments; an ethnological museum, a library of Ethiopica (the largest collection in the world based on material on the Horn of Africa and Ethiopia), and a research and publications department.

\section{IES Museum}

The IES museum's objective is to conserve Ethiopia's cultural heritage through displays reflecting material on the spiritual culture of the diverse nationalities of Ethiopia. The collection consists of ethnological culture displays, an art gallery, ethno-music, stamps, coins and bank notes. The collection was begun in the 1950s at the UCAA. After the founding of the IES in 1963, it moved to its new location on the main university campus. The collection was historically an ethnological one. An art gallery was developed in the mid-1960s due to a need to preserve a number of old Ethiopian art treasures and valuable church assets. By 1975, the year after the revolution which saw the overthrow of the Emperor, the museum had become the seat of the largest collection of Ethiopia's sacred art.

The museum has five elements which complement each other and represent the cultural and spiritual life of Ethiopians. The major collections are the art and ethnological collections, plus additional displays on sacred art, a music section, and a stamp and coin collection.

The ethnological section of the museum has samples of objects representing the diversity of Ethiopian culture, from agricultural implements, fishing and hunting tools to household objects, traditional clothing, ornaments and jewellery. Also displayed are religious icons and crosses (some date back to the 13 th and 14th century), Islamic calligraphy, church wall paintings and folk paintings. In addition there are photographs of stelae structures (obelisks), and religious architecture showing rock-hewn churches, castles and mosques.

Collections of sacred and secular art include paintings mostly on wood. There are some manuscripts and icon paintings. Icons depict traditional indigenous art of outstanding beauty together with samples of Ge'ez manuscripts and techniques of parchment preparation. The IES has also preserved medieval church artefacts including Lalibela crosses from the 12 th century, a painting of the Madonna (15th century), plus icons, triptyches, religious and folk paintings, different styles of religious crosses and other church objects.

The music section displays over 200 traditional musical instruments and has various recordings of traditional songs from all over the country. The museum is responsible for collecting and preserving musical instruments, including the Kerar, Begenna, Massenko, Washint, Embilta, Malaket and Kabaro. The stamp collection dates from 1894 to 1974 . The coin section contains 'primitive money' such as bars of salt and iron, coins from ancient Axum as well as 20th century modern coins and bank notes used in Ethiopia since the time of Emperor Menelik II. Restoration and conservation work is a valuable part of the museum's work in preserving the nation's cultural heritage. 


\section{IES Library}

On relocation to its own premises, shared with the museum on the main university campus, the IES library became a central resource for the staff and students of Haile Selassie I University, and continues this role today. The IES library is now one of several libraries on the university campus, including the Kennedy library (the main university library), OSSREA (Organisation for Social Science Research in Eastern and Southern Africa), and a law library. The IES library remains a specialist research library for AAU students, Ethiopian researchers and also academics from all over the world.

The library consists of an Ethiopian languages library, foreign languages library, manuscripts library, and archives. The main collection is 100,000 volumes strong, made up of books, periodicals, pamphlets and archives. It is a membership library, with an annual readership of 2,500 . It is a closed access reference library to prevent loss or theft of material. The library endeavours to collect all published material on Ethiopia, both from Ethiopia itself and also beyond its borders. The collection includes Ethiopian newspapers since their inception; Ethiopian manuscripts and microfilms of Ethiopian manuscripts held in foreign libraries; European and North American diplomatic papers relating to Ethiopia; photographs (historical and social); maps; letters (official and personal); tape recordings; university masters theses; senior essays (written by undergraduates); and extensive archives.

\section{Ethiopian studies}

The current IES library and its future modernisation represent the development of research and studies on Ethiopia dating back to the 17 th century and hopefully stretching well into the future.

An illustrious German scholar Hiob Ludolf pioneered research into Ethiopian studies in its modern sense in the mid-17th century. He never visited Ethiopia, but went to Rome to study the languages and history of the country by interviewing a small community of Ethiopian ecclesiastics. Ludolf was able to interpret the Ethiopian manuscripts written in the classical Ethiopian language of Ge'ez which he later mastered along with the vernacular Amharic languages. He also read virtually every book on Ethiopia published by that time including the memoirs of Francisco Alvares. (Alvares had spent 5 years in Ethiopia as chaplain of the first Portuguese diplomatic mission in the 1520s.) Ludolf also read the writings of Portuguese and Spanish Jesuits who came to Ethiopia in the 16th and 17th centuries to promote Roman Catholicism. He became well-acquainted with Ethiopian culture, at a distance, and published the first major history of Ethiopia, in Latin, in Frankfurt in 1681, later translated into English, French and Dutch and in 1691 he published a commentary on his history. He also published the first dictionaries and grammars of Ethiopic and Amharic languages between 1661 and 1699. Ludolf's correspondence still exists. Its translation into Amharic would be a significant bonus for the library and researchers.

Ludolf's work marked the beginnings of an important era in European studies on Ethiopia. Travel literature, important for introducing Ethiopia to the outside world, began with James Bruce (the explorer who discovered the source of the Blue Nile in 1770), and was a major development in the study of every aspect of Ethiopian history, society and culture. Bruce published his Travels to Discover the Source of the Nile (Edinburgh, 1790). Much was written also on the 
country's history based on Ethiopian royal chronicles, only known through Portuguese histories of Ethiopia. Bruce's visit was followed in the 19th century by the arrival of numerous other travellers initially from Europe and later from Russia and the US. European scholarly interest in Ethiopia soon aroused interest within Ethiopia itself. Emperors Tewodros and Menelik were very conscious of foreign reporting of Ethiopia.

The IES library has acquired a near-complete collection of travel writings. From easy availability 40 years ago, they are now more costly or else virtually unobtainable. However, there is a much weaker collection of travel articles which needs to be completed by microfilms of missing articles - such as James Bruce's diary entries now kept at Yale University, and from Italy, the Annales, in Latin, by the 15 th century Dominican monk Pietro Ranzano, preserved in the Biblioteca Communale in Palermo, Sicily.

Ludolf's research into Ethiopian languages was followed in the 19th and 20th centuries by other European scholars who helped extend the scope of Ethiopian studies on a global scale by publishing numerous tomes on Ethiopia's languages, history and society which found homes in the major libraries of the world. They are extensively covered in the IES library. However there are gaps. Donated copies from the Italian embassy of the writings of the major Italian scholars on Ethiopia are available. The IES welcomes other initiatives by foreign embassies where scholars have made a major contribution to the advancemient of Ethiopian studies, particularly in Arabic, and to work on collating and identifying non-English materials in foreign language bibliographies.

\section{Amharic Library}

The Ethiopian languages unit of the IES library holds a unique collection of books, pamphlets, leaflets, government documents, and a variety of periodicals and prospectuses in the Ethiopian languages of Ge'ez, Amharic, Orominga, Tigrigna, Kunamigna and Afar. There are 14,000 archival records, 290 photographic albums, 38,000 individual photographs, and 1,000 slides in the collection.

All serial publications produced in Ethiopia are collected and some of the titles on Ethiopia produced outside the country. It is a unique and comprehensive collection of 10,000 bound and 3,000 unbound periodicals of 600 titles. Titles include the fournal of Ethiopian Studies, the IES Bulletin, the Ethiopian Observer (founded by Sylvia Pankhurst), Abbay, Annales, Africa (Roma), Abbas and Paideuma. There are currently over 35,000 volumes available including material of rare historical and cultural value; a Holy Bible of 1701 (Ethiopian Calendar); early Amharic works on hygiene, agriculture, politics and administration; Amharic and Tigrigna newspapers; college and school magazines; research reports; with books and periodicals in local languages. Journal articles from the Fournal of Ethiopian Studies are currently being indexed on a database which will make them more widely available.

\section{Manuscripts}

Manuscripts are important for the study of Ethiopian history, culture and art. Broader subjects such as Oriental Christian literature and secular subjects of study such as history, philosophy, law, mathematics, music and medicine, all contribute to make the collection unique and important for Ethiopian studies 
and also for the wider study of African history and culture. While the majority are held in Addis Ababa and most are microfilmed, there are still some 5000 manuscripts believed to be held outside the country. Many have been taken abroad in the last 200 years. Multiple copies would be helpful and useful for authentication purposes and for establishing the author's accuracy and the identification of definitive texts

Microfilms are as important in the collection as books and articles. Two important sets of microfilm reels found in the library were arranged by the Swedes and the US. A Swedish grant enabled the acquisition of the principal European and American diplomatic archives on Ethiopia. The Italian Viceroy, Graziani's, telegrams on Ethiopia in 1936-7 are available on microfilm. There is also a unique collection of manuscripts, including over 3,000 Ge'ez, Amharic, Arabic and Adare manuscripts, and in addition $400 \mathrm{Ge}$ 'ez medico-magical scrolls.

The IES has acquired microfilms of manuscripts from outside Ethiopia with the assistance of the British Council and in collaboration with the embassies of the former Soviet Union and several European countries. Other European capitals hold rich collections of manuscripts of which Ethiopia would like to have copies or microfilms.

The IES holds about 1000 microfilm reels of European and US diplomatic correspondence relating to Ethiopia and the Horn of Africa. The library also holds over 7000 microfilm reels of Ethiopian manuscripts inside the country, and nearly 2000 from outside, including reels from the British Library collection, and six illustrated manuscripts from the Royal Library at Windsor Castle. There are reels of European manuscripts on Ethiopia, including Capuchin records, the D'Abbadie papers, the Church Missionary archives and the James Bruce papers. Reels of Ethiopian newspapers dating back to the beginning of printing in Ethiopia can be found plus microfilms of rare books and journal articles unavailable in their original form.

\section{Foreign Languages Library}

The IES library, foreign languages section, with material predominantly in English, German, Italian and French, consists of published and unpublished material on Ethiopia, comprising 30,000 books, monographs, pamphlets and conference proceedings, $2000 \mathrm{MA}$ and $\mathrm{PhD}$ theses, 10,000 senior essays and miscellanea.

Some rare items dating back to the 17th century are Hiob Ludolf's writings in Latin (mentioned above) and his Travels of the fesuits in Ethiopia, 1710 and Grammatica Aethopica, 1702. Some rare items from the Ethiopia collection include $A$ Life of Teklehaymanot in version of Debralebanos and The Miracles of Teklehaymanot ... with illuminated plates, 1906; The Miracle of the Blessed Virgin Mary and The Life of Hanna, with illuminated plates, 1661; The Lives of MabaSeyon and GebraKristos with illuminated plates, 1898. As well as material of a religious nature there is also secular material with diverse titles such as Wax and Gold (Levine, Donald N., 1965, University of Chicago Press); African Hairstyles of Yesterday and Today (Sagay, Esi, 1983, Heinemann, London); 'Early History of Ethiopian Horse Names' (Pankhurst, R.P., 1989, Paideuma 35, 197-206). Theses and student senior essays cover a wide range of subjects such as studies on indigenous languages and culture, studies of ancient religious manuscripts, technological aspects of development in Ethiopia, and health and social issues in indigenous culture. 


\section{Archives}

A new research centre, the Welde Meskel Research Centre in Addis Ababa, is a centre for public archives owned by the IES and salvaged from public agencies after the 1974 revolution, with archive material on litigation, properties, estates and land. The librarian at the time of the revolution saved many works including books, letters and photographs which would otherwise have been destroyed or lost. Ethiopian scholars have donated manuscript copies of their work to the library. The archives provide vital sources of information for researchers.

\section{IES Library organisation}

The growth of the collection has led to problems of cataloguing, classification and indexing. The libraries are indexed according to an archaic card catalogue indexed by author, title and subject, and inconsistencies in cataloguing and filing have crept in over the years. Catalogue cards often exist with no corresponding item on the shelf and vice versa. These anomalies need to be addressed in maintaining the collection and before any planned relocation. Articles from the fournal of Ethiopian Studies are indexed on a database, and books and monograph records are now catalogued and classified on a database in an attempt to move away from catalogue cards.

Variations in the transliteration of Ethiopian names into Roman script have been highlighted as a significant problem needing to be addressed in the future development of the library especially in terms of its automation. Amharic is a phonetic language and the spelling and writing of people's names is dependent on individual's pronunciation. The Wright system (named after the former Amharic unit librarian Stephen Wright) was introduced in the 1960s. Stephen Wright highlighted the idea of one sign, one sound, where one Ethiopian character is equivalent to one syllable and is equivalent to two letters of the Roman alphabet. This enables the transliteration of names and their precise conversion back to the original Ethiopian script. However the system has not been implemented consistently over the years due to increased numbers of cataloguing staff. This has inevitably led to problems with card indexing and filing and retrieval for library users who have to check multiple spellings of the same name.

Staff have been able to identify the full extent and scope of the collection, identify gaps, and explore means of acquiring missing stock with either the physical items or microfilmed copies or photocopies, by checking published bibliographies of European scholars. It is hoped authors, scholars of Ethiopia, publishers, foreign libraries, and foreign institutions such as the British Council, Addis Ababa University, Ethiopia National Library, British Library, British Museum, non-governmental organisations and US institutions will assist in

this part of the project. Volunteers are being sought to assist in the bibliographic checking of European language material for its availability and location.

To date it is estimated about $50 \%$ of the collection is missing, including monographs and articles. There are complete runs of Ethiopian journals, Fournal of Ethiopian Studies, IES Bulletin, and most journals concerned with Ethiopia or the Horn of Africa. Copies of other international academic journal articles will have to be acquired, bound and included in the collection. 


\section{Acquisitions}

Researchers and IES staff have produced a wish list of items to be included in the IES collection. This includes 15 th century Italian Dominican monk Pietro Ranzano's Annales in Latin, housed in Biiblioteca Communale in Sicily (Palermo). This would need to be obtained on microfilm together with other manuscripts held overseas such as the Magdala Collection in the British Museum. The Russians, Swiss, Irish, Swedes and Princeton and New York libraries in the US are also assisting in efforts to provide copies of ancient material held overseas. All such efforts are an important contribution to the historic, literary, cultural, religious and artistic studies of Ethiopia. Some manuscripts are inevitably still inaccessible to Ethiopia. Cambridge University library, the Bodleian Library in Oxford, and institutions in France, Germany, Italy and the Vatican, Spain, Greece and Israel all hold manuscripts, and the IES is looking to the EU for support in acquiring this material in order to establish a comprehensive manuscripts archive for Ethiopian studies.

\section{ICT developments}

The IES web site (www.ies-ethiopia.org) offers visitors an insight into the work of the Institute and a wider perspective on Ethiopia. This can be more widely used to promote the IES and encourage members and library readers/ researchers to contribute their work including theses and articles to the library to increase its coverage of published material on Ethiopia outside the country, and in its efforts to be a comprehensive deposit of Ethiopica.

The IES has close links with the University of South Florida (USF) in the US and the institutions are collaborating to establish a web-based national resource, the Ethiopia National Development Research Bank (ENDRB) to make research available on the internet, and therefore accessible to a much wider research community.

A digitisation centre will be set up at the IES in Addis Ababa to digitise and catalogue IES resources. For the library, its contents will be uploaded. Work has already started on digitising summaries and full-text versions of student theses. In addition there will be collaboration with the main Kennedy Library to make health-related electronic journals accessible. A resource-sharing system will be established through ENDRB for Ethiopian and global studies on Ethiopia. For the IES museum, collections such as rare music on records, rare wall painting and icons, microfilms of archives and rare documents including land deeds held outside the IES at Wolde Mesqal Memorial Research Centre will be digitised and made available in the research bank.

USF staff will come to Addis to train Ethiopian library and information staff in online cataloguing, and set up systems to facilitate the integration of older material with minimum time and effort and to set up consistent cataloguing and classification standards.

These exciting ICT developments will pave the way for Ethiopia to open itself up to the world (as it did formerly in the era of James Bruce) in terms of scholarly research, and the country and people will also benefit from increased exposure. However, at present the IT, power utility and telecommunications infrastructures are unstable and an IT culture has to be developed. While most people in urban areas are familiar with the internet and email and there is a proliferation of cybercafes around Addis Ababa, even where libraries and 
institutions are equipped with computers, technology is still not used to its full potential. But there is a curiosity and challenge for people to investigate and embrace new technology and new media.

\section{Links}

The Culture Africa Network (CAN) is a non-profit continental African project initiated by Contemporary African Music \& Arts Archive (CAMA) at the University of Cape Town. The centre, working as part of the IES in Ethiopia, aims to establish a multi-media network for African arts and culture on the continent. The CAN project also aims to facilitate awareness and pride in African heritage and to promote cultural creativity, African artists and musicians. Through multi-media documentation and culture sharing there is now collaboration among key cultural and academic institutions in several African countries, Ethiopia, Ghana, Mali, Sudan, Kenya, South Africa and Mozambique.

The Ethiopian CAN centre is to record and document painters, musicians and artists in the country, exchange with other CAN countries and serve as a centre for research in the area and as a learning place for students of music and art. To date two CDs of two painters have been produced and plans are to continue such activities in the future. The opening of the centre has been of significant advantage to the schools of art and music in Addis Ababa.

The IES is a key player in collaborative research projects with other international institutions of which the following have so far been initiated: SAREC/IES Microfilm Project (Sweden), South Omo Research Project, Comparative Studies on Indigenous Knowledge on the Environment in Ethiopian societies, Survey of Little-known Languages of Ethiopia (SLLE), Environment and Social Change in 20th Century Ethiopia.

\section{Research and Publications Unit}

The Research and Publications Unit at the IES is responsible for conducting, promoting and coordinating research and publications on Ethiopia with special emphasis on the humanities and cultural studies. The scope of the university's contribution is immediately apparent from the thousands of student theses held in the library, the majority based on research at the Institute. A further responsibility of the Institute is to host foreign scholars and assist in their research in Ethiopia, their contacts within the country and the provision of library services.

Research is disseminated through national and international conferences, lectures and talks. The conference proceedings held in the IES library consist of published material from conferences on Ethiopian studies. The International Conference on Ethiopian Studies is held every 3 years and organised by the IES. The first international conference was convened in Rome in 1959 and the XIVth International Conference was held in Addis Ababa University in 2000 and coincided with the golden jubilee of the founding of the university. The IES has the privilege of hosting one out of every 3 conferences. Conferences are made up of lectures, discussions and plenary discussions. The international conference covers a wide range of subjects including history and archaeology, linguistics, literature, anthropology, education, law and politics, development and the environment, religion and philosophy. There is also a national conference held annually, and other varied meetings including the International 
Conference on the History of Ethiopian Art, the 6th meeting of which was held at the IES in 2002.

The IES also organizes national and international conferences and interdisciplinary seminars on a wide range of specialist themes such as Ethiopian art. Other conferences arise from anniversaries to mark special occasions such as the centenary victory of Dogali, Adwa and the centenary anniversary of the founding of Addis Ababa. The IES also organises lectures and talks on relevant topics attended by members of the international, as well as the local, communities in Addis Ababa. These programmes are common features at the IES to promote Ethiopian studies and popularise the need for the preservation of Ethiopian cultural heritage.

The IES has two regular publications: fournal of Ethiopian Studies, the principal publication on research on humanities and cultural studies, and secondly the IES Bulletin which has been in publication for over thirty years and is of international renown. The IES Bulletin is a synopsis of news, views and activities on IES research. Other IES publications include conference proceedings, monographs and research reports.

\section{SOFIES}

The Society of Friends of the IES (SOFIES) was founded in 1968 and has had a major role in introducing both the Ethiopian and the international communities to many aspects of Ethiopia's culture. It has also played a role in raising funds for the IES museum. Fundraising has enabled the Institute to acquire religious artefacts and paintings and manuscripts to maintain the museum as the finest gallery of Ethiopian traditional art in the world. At the same time it has saved works of Ethiopian art for posterity which would have been lost abroad. SOFIES holds regular lectures and slide shows, mounts exhibitions such as Victory through Struggle, 1977; Tenth Anniversary of the Ethiopian Revolution, 1984; 120th Anniversary of the Battle of Maqdala, 1988; African Zion Exhibition (joint touring exhibition with the National Museum organised for various American states). SOFIES membership allows free access to the museum and library.

\section{The Association for the Return of Ethiopian Maqdala Treasures (AFROMET)} AFROMET campaigns for the restoration of artefacts looted in the 19th century and now held in the Queen's Collection at the Victoria \& Albert Museum and the British Museum in London, and other museums around the world. British campaigners would like the treasures to be returned to the Ethiopian people for display rather than kept in their present locations under lock and key away from the public gaze in London. Some treasures have already been returned including tabots (sacred boxes bearing replicas of the ark of the covenant), Emperor Tewodros' amulet and a tablet. Italy is negotiating the return of the obelisk looted by Mussolini.

\section{1st Century Library}

The library, growing steadily since its inauguration in 1963, has now after 40 year outgrown its space at the IES in Haile Selassie's former palace. SOFIES is pioneering the development of a new fully automated purpose-built 3-storey library, giving back the existing library space to the museum. The new library's foundation stone has already been laid by the President of Ethiopia, the architect's plans are completed and major fundraising ideas are being sought. 
But what should be in an Ethiopica library in the modern age in the 21 st century when resources are held outside Ethiopia and indeed Africanists have to travel widely across several countries and maybe several continents to track down sources such as microfilm copies of James Bruce's notebooks. Automating the new library facilities will enable its resources to be available both locally and globally. The new library will continue to maintain and develop the existing IES collection, fill identified gaps, expand the collection into new diverse areas, modernise library functions and increase accessibility of the unique Ethiopica collection to Ethiopia and the world.

The current library collection has traditionally concentrated on Ethiopia and the Horn of Africa as its target audience and for the scope of its collection. As Ethiopian studies and the number of scholars increases, the IES must broaden its remit to consider Ethiopia's position and role in the region and the world. Ethiopia's historical links with the Yemen, Sudan and Kenya need to be addressed in terms of related historical studies and civilisations. Other languages, such as Arabic also need to be accommodated.

The collection also needs to examine Ethiopian history from an Ethiopian perspective and consider Ethiopian influences beyond its borders. Foreign and external influences on Ethiopia dating back to prehistoric times can provide a comparative view of world history and culture, bringing Christianity, Islam, Europe, Asia, and the role of the Jesuits (in Ethiopia and other parts of the world) to the fore. Ethiopia's role in the modern era as a founding member of the Organisation of African Unity (OAU), now the African Union (AU), and also the United Nations, should be addressed by collecting literature on these institutions.

\section{The Future}

The latest challenge in Ethiopia is the growth of universities across the country. The IES and the university in Addis Ababa now have a new role in serving not only staff and students in the capital but people in other parts of Ethiopia and also serving interested parties on an international level. The launch of the project for the 21 st century library will contribute to the growth of numerous universities in Ethiopia and the development of library services across the country. IES library material must be made available, across the internet, to the various campuses of $\mathrm{AAU}$, and to all higher education institutions. Electronic access will also be made available to government offices, cultural and educational institutions around Africa and the world. As a founder member of the United Nations, and a host of the headquarters of the UN Economic Commission for Africa, and the former Organisation for African Unity now the African Union, Ethiopia's pivotal role in Africa has already been recognised. Also with the development of the existing IES mandate and the plans for the 21 st century library, a new era and new direction will begin in Ethiopian studies which will impact on the future of higher education in Ethiopia and the African continent.

\section{Acknowledgements}

The author would like to thank IES staff for their help and support, as well as Ato Solomon Desalegn, Professor Richard Pankhurst and Rita Pankhurst. 
xviii Introduction

Links \& further reading

www.ies-ethiopia.org

www.addistribune.com

www.ethioembassy.org.uk

www.allafrica.com

Ethiopia: the Bradt Travel Guide

Philip Briggs, Bradt, 2001

\section{A History of Ethiopia}

Harold G. Marcus, University of California Press, 2002

Notes from the Hyena's Belly: An Ethiopian Boyhood

Nega Mezlekia, Picador, 2001

\section{Under Ethiopian Skies}

Graham Hancock, Richard Pankhurst, and Duncan Willetts, H\&L

Communications Ltd, 1983 